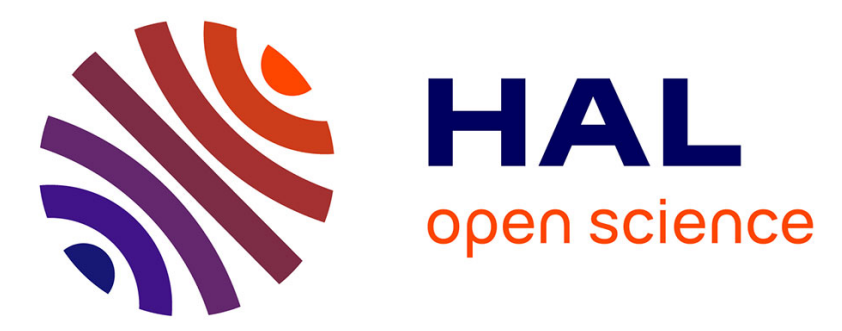

\title{
Living with numbers: Accounting for subjectivity in/with management accounting systems
}

Eric Fay, Lucas Introna, François-Régis Puyou

\section{To cite this version:}

Eric Fay, Lucas Introna, François-Régis Puyou. Living with numbers: Accounting for subjectivity in/with management accounting systems. Information and Organization, 2010, 20 (1), pp.21-43. 10.1016/j.infoandorg.2009.10.001 . hal-00771160

\section{HAL Id: hal-00771160 https://hal.science/hal-00771160}

Submitted on 11 Dec 2013

HAL is a multi-disciplinary open access archive for the deposit and dissemination of scientific research documents, whether they are published or not. The documents may come from teaching and research institutions in France or abroad, or from public or private research centers.
L'archive ouverte pluridisciplinaire HAL, est destinée au dépôt et à la diffusion de documents scientifiques de niveau recherche, publiés ou non, émanant des établissements d'enseignement et de recherche français ou étrangers, des laboratoires publics ou privés. 


\title{
Living with numbers: Accounting for subjectivity in management accounting systems
}

\author{
Eric Faÿ ${ }^{\mathrm{a}, 1}$, Lucas Introna ${ }^{\mathrm{b}}$, François-Régis Puyou ${ }^{\mathrm{c}}$ \\ ${ }^{a}$ EMLYON Business School, 23 avenue Guy de Collongue, 69134 Ecully Cedex, France \\ ${ }^{\mathrm{b}}$ Lancaster University Management School, Lancaster LA14YX, U.K. \\ ${ }^{c}$ Audencia, Nantes School of Management 8 route de la Jonelière, 44312 Nantes, France
}

${ }^{1}$ Corresponding author. EMLYON Business School, 23 avenue Guy de Collongue, 69134 Ecully Cedex, France, Tel.: +33-4-7833-7738; Fax: +33-4-7833-7928. E-mail addresses: fay@emlyon.com (E. Faÿ), 1.introna@lancaster.ac.uk (L.Introna), frpuyou@audencia.com (F.-R. Puyou). 


\title{
Living with numbers: Accounting for subjectivity in management accounting systems
}

\begin{abstract}
The disembodying and disembedding of work through systems of abstraction (such as management accounting systems) were fundamental to the establishment of regimes of management that act, not directly and immediately on others, but instead acts upon their actions-i.e. the establishment of management as a regime of governmentality. Timespace distanciation, through abstraction (such as numbers) and electronic mediation, has radically transformed the way organisational actors interrelate and make sense of their everyday organisational lives. This paper argues and shows that phenomenology, in particular the work of Michel Henry, can help us understand how actors live their lives in and through the simultaneity of systems of abstraction and their affective, embodied and situated living praxis. The paper presents a case study of how different organisational actors (managers and controllers) make sense of, and live with, the numbers in a management accounting system-numbers that affect them quite profoundly. The analysis of the case shows that all interpretation, sense-making and argumentation of, and with the numbers are rendered possible through re-embodiment. Such a reembodiment, in turn, require as necessary a prior reference to their subjective affective life-their own living praxis. If this is the case, as we hope our research shows, then subjective affective life should not be subjugated by the formal rational discourse of management but should rather be seen for what it is-the very source of meaning that is the condition of possibility for abstraction and mediation to be possible at all. The paper concludes with some implications of Henry's phenomenology of life for organisations and management research.
\end{abstract}




\section{Introduction}

It is widely acknowledged that the development and utilisation of management accounting systems (MAS) was fundamental to the emergence of the industrial socio-economic infrastructure (Hopwood, 1987; Fleischman \& Tyson, 1993). It is possible to argue that it is MAS's ability to translate broad economic principles into directly actionable operational imperatives, which can direct and govern action, that locates MAS at the centre of managerial intentions. As a technology of control that renders action visible it constitutes what Foucault (1997) might call a regime of governmentality. As a regime of governmentality MAS constitutes "a mode of action that does not act directly and immediately on others. Instead, it acts upon the actions of others, and presupposes the freedom to act in one way or another" (Miller, 2001, 380). Through the mediation of MAS distant actions become visible and amenable to intervention. As a technology of governance the numbers in MAS are always already imbued with social significance as they render visible strategic and operational intentions and actions. As Miller argues:

The calculative practices of [management] accounting are always intrinsically linked to a particular strategic or programmatic ambition. Accounting practices are endowed with a significance that goes beyond the task for which they are deployed. ... it is through them that accounting comes to appear essential to the government of social and economic life. Attention is thus drawn to the reciprocal relations between accountancy and the social relations it forms and seeks to manage. The calculative practices of accounting are intrinsically and irredeemably social. 
If this is true, as it is so self-evidently for most managers, then MAS are at the very centre of governing the intentions, aspirations, beliefs, etc of many if not most organisational actors. Given this organisational and social significance of MAS we would suggest that the question of the subjective engagement with numbers, as rendered possible by MAS, is fundamental to our understanding of how these systems actually govern organisational life, especially, we will argue, with regard to subjectivity. Not only with regard to the social construction of subjectivity as has been done for example by Miller \& O'Leary (1987) and Hopwood (1987), but more importantly, with regards to subjective life itself through the affective experience of being confronted with a 'numbered' world. This is the focus of our paper.

We want to suggest that through information technology it has become possible for MAS to be deployed to govern the most intimate minutia of daily organisational life. Through an ever-increasing process of abstraction this has led to the progressive disembedding of the local singular and situated subject to a more globalised governed subject or agent. However, ultimately decisions and actions have to return to the domain of the local singular and situated subject for them to be individually and socially significant. It is in this regard that we believe phenomenology can and should play a role. We want to propose that through phenomenology, in particular the work of Husserl (1970) and Henry (1973, 1983, $1998,1999,2003,2004)$, we can give an account of the consequences of the 'mathematization' of organisational life-and in particular the way individuals deal subjectively with this 'mathematization' in everyday organisational life as lived. We will show how phenomenology, specifically the work of Michel Henry, can help us 
understand how actors live their lives in and through the simultaneity of systems of abstraction and their affective, embodied and situated living praxis.

In order to do this we will structure the paper as follows. In the first section we set out the theoretical landscape within which our work is located. We draw on the work of social theorist Anthony Giddens(1984, 1990, and 1991), specifically his notion of time-space distanciation. We argue that this is a primary phenomenon for organisation studies and indicate how different authors have taken it up in their work as well as locate our work relative to it. In the second section we elaborate phenomenology, in particular the work of Husserl and Henry, as our theoretical horizon. We suggest that ultimately all disembedding (through time-space distanciation and abstraction) require, as an inescapable necessity, individuals to re-embed, and even re-embody, abstract mathematical representations in order for these to be encountered as information-information as inward forming in the sense proposed by Boland (1984, 1987, 1993b) and others (Introna, 1997; Weick, 1988, 1993, 1995). To support this argument we will present, in section three, the Omega case study of the implementation of a MAS. In reviewing this case study we will argue that abstract numbers are always perceived affectively as a supplementary and distinct mode of perception to vision and re-presentation. This review of the Omega case will be followed, in section four, with a discussion in which we clearly show how the affectedness of the individual managers condition their singular experience of abstract numbers in order for the MAS to have social significance, as argued by Miller (2001) and Jones \& Dugdale (2001). In the final section we conclude that our contemporary understanding of the organisational reality of work -as increasingly mirrored in abstract systems of representations 
(particularly IT mediated representations) — needs to take account of the insights provided by Henry's phenomenology.

\section{Abstraction, time-space distanciation and the disembedding of the subject}

Abstraction $^{2}$ is fundamental to achieving access and control across time-space boundaries or localities. Through abstraction it is possible, in some particular way, to disembed the singularity—event, practice, individual, etc.—both with regard to time and space. For example, with the aid of the abstraction that language provides one can refer to a person, a time, and a location, in a time and place other than that in which it occurs when it occurs as a singularity. It is possible, for example, for me to say "I saw Jim Smith yesterday at the university shop" and in so doing provide a certain type of access to that singularity (Jim and I at the university shop) to a third person who were not present in the singularity of the event. Without this type of mediated access-made possible through the abstraction of language in this case- -knowledge and agency will only be possible in the singularity of the event as such. One would need to be there in the singularity of the event, as and when it happens, as such, to know it or to control it in anyway whatsoever. Thus, abstraction allows us to escape or transcend, in a very specific way, the specificity and embeddedness of the here and now.

\section{Giddens, time-space distanciation and the reflexive subject}

Giddens (1984, 1990, and 1991) calls this process of disembedding, through systems of abstraction, 'time-space distanciation.' Time-space distanciation,

\footnotetext{
${ }^{2}$ By 'abstraction' we mean the process (or result) of generalization where the phenomena in question are reduced to some essential element seen as relevant (or useful) in a particular context. For example number, as an abstraction, reduces phenomena to be revealed as quantity. Money, in the form of wages, reduces labour to an exchange value, and so forth.
} 
according to him, allows us to lift out social activities from specific localized contexts and reorganise them across wider time-space horizons, or differently stated: it is "the conditions under which time and space are organized so as to connect presence and absence" (1990, 14, emphasis added). This everincreasing interpenetration of presence and absence (through symbolic systems of abstraction, such as language, figures, money or information flows more generally) is, according to Giddens, a particular and distinctive feature of late modernitywhat he calls reflexive modernity. In reflexive modernity "place becomes increasingly phantasmagoric - locales are penetrated by and shaped in terms of social influences quite distant from them" (19). He also suggests that the essential aspects of time-space distanciation are expressed well through the notion of 'globalisation' where globalization is understood as "the intersection of presence and absence, the interlacing of social events and social relations at a distance" (1991, 21)—see also Tomlinson (1999) for similar arguments. Although many are critical of Giddens' epochal analysis there is general agreement that his analysis of time-space distanciation identifies a very important modality of social organisation (irrespective of epoch)—and one might argue a modality central to the ongoing emergence of contemporary, increasingly global, organisations.

As suggested above, time-space distanciation, through systems of abstraction, allows for the construction of the third person perspective (in our case the managerial perspective). Without this disembedding process, which abstraction makes possible, management as a third person perspective and information and communication technology as systems for the production and dissemination of abstractions would not have evolved to its current central position in organisational 
discourse and practice. Taylor, the father of modern management, understood this very well. In The Principles of Scientific Management (1911) he explains this movement from the embedded singularity to the development of abstract principles in order to manage and control work practices across time and space:

To explain briefly: owing to the fact that the workmen in all of our trades have been taught the details of their work by observation of those immediately around them, there are many different ways in common use for doing the same thing... Now, among the various methods and implements used in each element of each trade there is always one method and one implement which is quicker and better than any of the rest. And this one best method and best implement can only be discovered or developed through a scientific study and analysis of all of the methods and implements in use, together with accurate, minute, motion and time study. This involves the gradual substitution of science for rule of thumb throughout the mechanic arts. (pp 24-25, emphasis added)

Through these 'scientific' abstractions a mode of action comes about that does not act directly and immediately on others (locally in the singularity) but instead acts upon their actions as rendered visible through these abstractions-i.e. governance at a distance, or more specifically governmentality, becomes possible (Foucault, 1997).

Through the scientific study, and codification, of work practices-as well as the automation and informatisation (Zuboff, 1989) of these practices through IT-there has been a massive intensification of the process of abstraction and with it unparalleled opportunity for time-space distanciation. The potential for time-space distanciation through information and communication technology was evidently 
understood by those that marketed the early telephone as this AT\&T advertisement from 1933 clearly demonstrates:

A neighbor, passing by, glances through your window and sees you in the livingroom. But you are around the corner on Main Street, ordering from the druggist. You are in a nearby town chatting with a friend. You are in a distant city, delivering a message of cheer and assurance. You are across a continent, or an ocean, talking clearly and easily, as if distance had ceased to be. . . Your telephone is you. In a moment it multiplies and projects your personality to many different places and many different people, near or far. Part of your very self is in every telephone message - your thoughts, your voice, your smile, your words of welcome, the manner that is you. You use the telephone as you use the power of speech itself, to play your full part in the world of people. With it in your grasp, you are master of space and time. You are equal to emergency, ready of opportunity, receptive to ideas, equipped for action. The extraordinary fact is that the more you use your telephone, the more it extends your power and personality. (AT\&T print advertisement, July 1933)

The growth and development of management (as process and practices) is directly related to our ongoing ability to build systems for the production and dissemination of codified abstractions-i.e. for time-space distanciation. Indeed, Giddens insists on the role initially played by mechanical devices such as clocks and maps to turn time and space into standardized entities removed from the immediacy of context (1990)_and to this we may also add ongoing digitization of work practices (such as CAD/CAM, ERP, GIS, etc.). It is therefore not surprising that the scope and reach of management (as a process of governmentality) is directly connected with the ongoing development and dissemination of information 
and communication technology. Through abstraction and codification action upon the actions of others itself becomes globalised. Kalinikos (2006, p. 22) captures this idea well when he suggests that: "An expanding number of domains of palpable reality are carried, in surrogate forms, on the shoulders of technological informatization that describes, renders or constitutes, controls and monitors different aspects of social and institutional life. In thus making reality pliable and mobile, informatization has been an important precondition for the diffusion of alternative administrative models and work patterns."

Disembeding and distanciation through abstraction and codification is, however, just one side of the enactment of governmentality or one side of time-space distanciation. Distanciation enables but it also constrains. One might argue that the process of disembedding ultimately needs to be reembedded and localised in some way or another. The distanced organisational actors (managers and employees) need, in some way, to reembed, reembody or resituate the abstractions and codes they encounter in their information systems. Without such a 'reversal' or retranslation the systems of abstraction-the MAS in our casewould not function as a modality for governmentality. In this regard Giddens (1990, p.86) suggests "facework rituals" as very important for individuals living in disembedded institutions to pin down distant relations to local conditions of time and space. Face to face encounters are necessary to bracket distance and time, block off anxieties and organize reliable interactions across time-space. Giddens (1990) also acknowledges the fact that "trust in abstract systems is not psychologically rewarding in the way in which trust in a person is" (p.113) and 
argues that there is a need to develop trust on a personal level. ${ }^{3}$ Thus, time-space distanciation is a bidirectional phenomenon where presence and absence continually intertwine (or interpenetrate); as such it enables and constrains both autonomy and subjectivity.

In conclusion, we would argue that although Giddens provides a compelling conceptual analysis of time-space distanciation, his high level analysis lacks empirical detail. In particular his analysis of the reflexive subject of late modernity does not provide an adequate account of how the living affected subject deals with the mutually interpenetrating simultaneity of presence (local, situated) and absence (global, abstract) as an ever-increasing fact of everyday contemporary life (across all social institutions). This is precisely the aim of our research reported here.

\section{Some existing studies on time-space distanciation}

It should be acknowledged that there are a large number of studies (and debates) within the IS and Organization Studies literature that has directly (or more indirectly) attempted to provide more detailed empirical studies of particular instances of technologically mediated time-space distanciation. For example Jin and Robey (2008) have, in their study of iTalk, expanded Giddens' analysis from social relations to technical artefacts/systems, more specifically, in order to show that these also require some form of reembedding to function appropriately. They argue that disembedding technologies in iTalk create new capabilities but also unexpected conflicts. They demonstrate that reembedding is highly situated.

\footnotetext{
${ }^{3}$ Giddens quotes Deirdre Boden's example of the academics who cross continents to attend conferences in order "to see the whites of the eyes of colleagues and enemies alike, to reaffirm and, more centrally, update the basis of trust" (1990, p.87).
} 
Successful embedding of external interfaces resulted in problematic distant internal interfaces-thereby highlighting the social and technical conditions (especially the political aspect) that shape the reembedding of relations across time and space.

More generally one could argue that time-space distanciation is perhaps one of the most central organisational phenomena for management and organisation studies. As such it is possible to find many studies that attempt to account for it in more or less significant ways. It is beyond the scope of this paper to review all of these. We will however highlight a few strands of this work in order to locate our work. For example, actor network theory (Walsham, 1999; Scott and Wagner, 2003; Frandsen, 2009) deals with this phenomena by attempting to understand how technologically mediated actants enacts the global and abstract (safety regulations and intentions, for example) in the local practices (seat belts and ignition systems) in order to enrol local actors in distant programmes in more or less successful ways (Latour, 1992). Others treat time-space distanciation as a problem of representation (Cooper, 1992; Kallinikos, 1995; Lilley et al., 2004, Townley, 1995). According to Lilley et al (2004) information technology in organisational settings functions to 're-present' things (or render present that which was or is absent)—as such 'their 'natural' presence is substituted by a technologically mediated presence elsewhere" (p.24). Another strand of research views time-space distanciation as a phenomenon (or problem) of virtualisation (Sotto, 1997; Schultze and Orlikowski, 2001; Robey, Schwaig, and Jin, 2003; Panteli, 2004). For example Introna (2001) argues that virtualisation will always be constrained by the situated and embedded nature of social practices. Similarly, 
Robey et al (2003) show, in their study of virtual teamwork, that presence and absence needs to be intertwined sufficiently for meaningful distanciated collaborative practices to exist. Finally, and most relevant to us, is the way in which presence and absence conditions ongoing interpretation and sense making in conditions of time-space distanciation (Boland, 1983b, 1991 and 1993a; Weick, 1988, 1995).

Boland and Weick were among the first to focus explicitly on the problem of interpretation and sense-making as it emerged in managers (and employees) having to deal with the problem of increasingly encountering the action (of others that they are concerned with) through systems of abstraction and codification. In their critique of the process of abstraction and codification (or mathematization) Boland (1983b) suggested that our systems of abstraction and codification did not contain 'information' since the very essence of information already implies a subject that is inwardly formed. In other words our supposedly 'informing' systems through its abstraction and codification had already in some way disembedded or lost its subject (or more precisely its subjectivity). He further showed that when managers encountered supposedly 'objective' accounting information they will always implicitly reembed these abstractions and reimbue them with subjective life through a process of ongoing, mostly implicit, interpretation (Boland, 1993b). His work explicitly and implicitly connected to the more general philosophical debates on the problem of interpretation or hermeneutics as reflected, for example, in the work of Dilthey and Gadamer (Palmer, 1969). Boland's work and others that have followed this line of inquiry (Boland \& Pondy, 1983a; Thomson et al., 1989; Dreyfus, 1991; Introna, 1997; Gabriel, 2002; Ciborra, 1998, 1999, 2000, 2004) 
brought the problem of the subject (or subjectivity), and the embodied subject (Mingers, 2001) that these systems of abstraction and codification had in some sense 'lost or forgotten' back into consideration. More specifically it brought the problem of the ongoing perceptual engagement of the subject in an increasingly abstract and globalised world into focus. With this move phenomenology emerged as an important resource for understanding the subjectivity of the subject in dealing with informatized abstractions. ${ }^{4}$ Unfortunately, due to the technical language of phenomenology these very fruitful early attempts never found its way into the mainstream research of accounting and information systems. In the next section we want to recover some of these origins in order to show that they are still very relevant and necessary to account for the 'distanced' and governed subject at the centre of every MAS.

\section{Phenomenology, mathematization and being affected}

In this section we want to show that phenomenology, in the work of Husserl, can give an account of the mathematization of the lifeworld more generally, and that phenomenology, in the work of Henry, can help us to understand how individual actors become affected by these systems of abstraction and codification in the lifeworld of ongoing everyday organisational life. In a first instance we want to show, with Husserl, that the mathematization of organisations has emerged in management practice, and more specifically in MAS, as part of a broader history of ideas and practices which both enabled and legitimated it. After that we will introduce the phenomenology of Henry which enables us to articulate

\footnotetext{
4 Phenomenology has also been identified by non phenomenologist as a central complement to their frameworks. Indeed, a chapter in Giddens' book The consequences of modernity (1990) is dedicated to a 'Phenomenology of modernity' (p.137). This chapter deals with the mediation at a distance between intimate relationships and the sense of familiar though abstract systems.
} 
organisational actors' embodied lived experience and the way they deal with abstract representations through interpretation as suggested by Boland (1984; 1987).

\section{Husserl and the mathematization of knowledge and action}

In The Crisis of European Sciences and Transcendental Phenomenology (1936 translated 1970) Husserl traces back to Galileo the emergence of a "theoretical logical praxis" disconnected from "our bodily way of living" (50). According to Husserl, "Immediately with Galileo, then, begins the surreptitious substitution of idealized nature for prescientifically intuited nature" (1970: 49-50). Knowledge is no longer bound to the uniqueness of situations, but sees the world through a prism of idealized forms and geometric models. The lifeworld, the world which we perceive subjectively through our senses, is substituted for a world of geometric and mathematical forms, which is now perceived as the original and legitimate lifeworld. This theory of knowledge also gives rise to a specific theory of action. Instead of the real praxis - one concerned with empirical reality, we are now faced with an ideal praxis, "of 'pure thinking' which remains exclusively within the realm of pure limit-shapes" (1970: 26).

If one has the formulae, one already possesses, in advance, the practically desired prediction of what is to be expected with empirical certainty in the intuitively given world of concretely actual life, in which mathematics is merely a special form of praxis.(1970: 43).

Thanks to this prediction and anticipation, made possible by mathematics, the ideal action can be carried into real life. The perfect nature of this type of action is justified by the exactness of the calculation-i.e. we can know for certain. As we 
have suggested above through the 'exactness' of numbers, and the distributive capacity of information technology, MAS provides the users with a supposed confidence to act according to the abstract optimized efficiency of this new limitshape (see also Hummel, 2006). It locates the question of exactness in the mathematical calculations and, in doing this, constitutes subjectively lived experience as potentially in 'error.' As Brunsson (2006) puts it "the [abstract rational] principle shows that the reality is wrong rather than the reverse. The practice is wrong, then, because it does not follow the principle" (115). However, as Husserl points out, the logical consequence of this perspective is that it leaves no room for life.

In his view of the world from the perspective of geometry, the perspective of what appears to the senses and is mathematizable, Galileo abstracts from the subjects as persons leading a personal life; he abstracts from all that is in any way spiritual, from all cultural properties which are attached to things in human praxis (1970: 60).

We would suggest that Husserl's analysis of the mathematization of the life-world shows very clearly the cultural-historical context in which scientific management as well as the technology of MAS, as a mode of governmentality, emerged as entirely legitimate, even necessary. In such a cultural-historical context it would not be surprising for idealised limit-shapes (in the form of cost data provided by the MAS) to become the privileged 'exact' reality that displaces the intuitive experience of the life-world and generates what Hummel (2006) calls the mismeasures of management. If this is the case then one might ask how it is possible to account for the way organizational members live (or not) their intuitive and subjective 
experience of life-world and their experience of numbers? To answer this question we propose that we turn to the phenomenology of Henry.

\section{Henry's phenomenology}

The fundamental thesis of Henry's phenomenology, as predominantly expressed in The Essence of Manifestation (1963; translated 1973), was to argue for two distinct but intertwined modalities of perception of phenomena. The first modality, very familiar to us, was 'seeing' or perceiving the objects at a distance, in which case objects appear to us in the light of our intentional behaviour; or merely during the course of actions we are engaged in. MAS are, as we have suggested above, a technology to make objects of interest appear to us at a distance through mathematical representations. It creates meaning by placing actual results under the light of some intentional expectations and/or previous achievements. The second modality of perceiving, of which we are mostly unaware, is affectivity or affectedness. In Henry's phenomenology the emphasis is on the fact that our living body, being an affective body (flesh in his terms), is the source of another form of knowledge that is entirely different from the one that comes to us through representations. In the whole spectrum between, tough or pleasant effort, or between joy and suffering, affectivity or affectedness leaves no distance between us and our affective perceptions. It is wholly immanent, in Henry's terms.

Affectivity or affectedness is not only supplementary to the 'seeing' of objects but it is also distinct from it as an always inescapable mode of perception. In other words, as incarnate beings, there is no way for us not to be affected. Thus, with Henry, we would claim that abstract numbers and other representations are not 
only perceived cognitively but always also affectively. Indeed we have all experienced that 'good' or 'bad' numbers or figures truly affect us in the flow of everyday life. However, we are not affected because they are 'good' or 'bad', rather, experiencing them as 'good' or 'bad' already presupposes our affectedness. $^{5}$ In proposing Henry's account of the duplicity of perception, especially our affectedness, we are not trying to argue for the role of emotions or feelings in reason, as has been done in many recent and useful contributions (such as for example the work of Damasio (1994)). We are rather claiming, more radically, that affectedness is the inescapable condition of being human. Indeed, it is the very possibility of human experience as such (Henry, 1963; translated 1973).

In their work Boland (1993b) and Boland and Pondy (1983b) have argued that the ongoing situated lived experience of the individual is already implied in any interpretive or sense making process. It seems likely that Henry would agree with Boland in stressing the necessary engagement of lived experience in the interpretation of abstractions. However, he would further argue, that dealing with abstractions is not only an interpretative problem-in the sense of creating an appropriate representation or framing (through cognitive scheme, culture, language, etc.). He would suggest that such interpretive process is also intertwined with subjective life, which is affectively lived through the inescapable and various affects of effort, pain, joy, etc.

\footnotetext{
${ }^{5}$ Embodied affectedness, as Henry suggests, is the way our life manifests itself to ourselves-what he calls auto-affection.
} 
We want to propose that this connection between the interpretation of representations and affective perception has not yet been adequately accounted for in organization studies (Linstead and Westwood, 2001). We would argue that from the very beginning affectedness is already implied in the perception of lived experience as such-without it lived experience would not be 'lived'. Affectedness constitutes the conditions of possibility of lived experience and lived experience constitutes the conditions of possibility of any interpretive or sense making activity to be meaningful as proposed by Boland $(1984,1987)$ and Weick (1988, 1995) amongst others. Henry's phenomenology also helps us go one step further. It allows us to grasp the way individuals relate to the world of idealised shapes (which Husserl identified) and to their subjective life simultaneously.

Let us take for example the experience of exceeding a target expressed in numerical limit-shape (such as a sales budget). We might experience the excitement of seeing our performance exceed expectations but we also often simultaneously and paradoxically find ourselves overwhelmed by a sense of malaise. Why is this simultaneity? When figures are far better than expected the excitement comes from the positive difference between the figure $x$ (horizon of expectation) and figure $y$ (achievement). In the light of the horizon of expectation this difference seems exciting. However, often a sense of malaise immediately emerges as we experience the gap between the reduction/abstraction the figures represent-as idealised limit-shapes-on the one hand, and our affective perception of the lived situation on the other hand. To focus on the abstract figures alone would be to attempt to silence our inescapable condition of living as a being that is affected. Thus, in our example, the malaise comes from the attempt 
to hide, through mathematical reductions, what appears in the light of our affective life. This malaise is especially reinforced when we have had to experience the 'destructive moves' or the very painful efforts that might be necessary to reach such 'excellent results'. Thus, going a step further, we will suggest that Henry will enable us to get a deeper understanding of malaise, as experienced by subjects in a landscape of abstract codifications.

Let us also stress with Henry that the being of being human means ultimately to experience ourselves affectively as being alive. ${ }^{6}$ From this foundation Henry argues that, as living beings, we are all inhabited by the dynamism of development and expansion of our embodied affective life-what he calls our teleology of life. ${ }^{7}$ In the teleology of life pain, malaise and suffering emerge as that which opposes the dynamism of one's affective life. In Henry's view, our everyday action should be considered, first and foremost, as a manifestation of one's living praxis - as an ongoing fully immanent subjective experience of effort, joy and suffering ${ }^{8}$ according to one's own singularity. Thus, the horizon of one's living praxis ${ }^{9}$ is intertwined but totally different from the expanding world of objective knowledge or representation-what one might call the teleology of abstraction. According to Henry this living praxis, internally informed and empowered by the teleology of

\footnotetext{
6 "In the immanence of its own pathos, the reality of life.... is everything except what contemporaneous thought will turn it into, that is, some impersonal, anonymous, blind, mute essence. In itself the reality of life bears necessarily this Self" (Henry, 1999: 353)

${ }^{7}$ Henry is here very close to Schopenhauer, Nietzsche, Deleuze and Macyntire. They argueagainst the philosophies which claimed the superior power of the intellect-that affective life is the dynamic principle of knowledge, intelligence and action.

${ }^{8}$ In Henry's view action is not to be first considered, from the outside, as a process; nor, in an Hegelian way, as an exteriorisation of our subjectivity

${ }^{9}$ With 'living praxis' Henry (1983) means: "Praxis designates the internal structure of action as it excludes from itself the objectification process, all distancing, all transcendence in general. What is held to be real, consequently, will be ... whatever experiences itself immediately ... What is real, therefore is need, hunger, suffering, labour too..." (p. 160)
} 
one's life, is achieved through cultural, spiritual or ethical praxis which enables different ways of experiencing the good life. Such living praxis is fully assured-as in giving full confidence-since it is never divorced from itself (and from what empowers it). Hence, the experience of malaise can then be understood as the expression of a gap between the teleology of abstraction, and one's teleology of life. $^{10}$

How might individuals respond to this experience? Henry suggests that although our lived experience is always to some degree determined by the structural conditions we find ourselves in-and MAS is one such structural condition-we are first and foremost already in the teleology of our affective life. Malaise, pain, joy is already a critical standpoint necessary to overdetermine these structuring determinations. Given this primacy of the teleology of live, and the privileging of the teleology of abstraction in contemporary organisational life, one may ask: how do managers and controllers live affectively with this simultaneity of the teleology of their life and the teleology of abstraction? How do they, in the singularity of their affective living, overdetermine it (or not)?

In the next section we will look at the Omega case study to reveal some of their ways of dealing with this simultaneity. It is our claim that Henry's phenomenology will enable us to give a more subtle and detailed account of the re-embedding process through "reciprocal relations between accountancy and the social relations it forms and seeks to manage" Miller (2001, 380).

\footnotetext{
${ }^{10}$ When money is fetishized and/or when one manages only through mathematical figures, in line with a theoretical logical praxis, then the MAS and the actions it aims to engender may be interpreted as a way to stand for, or to deny, the very dynamism of the praxis of living beings.
} 


\section{Living with MAS: The Case of Omega}

In our case study we will show employees of a company Omega share representations of common interest using a Management Accounting System (MAS). While they all acknowledge the usefulness of the system, they are all deeply affected by the discrepancies between the formal representations they use on the MAS and their own lived experience. Then, how do they, through the dynamism of their own affective life, subjectively make sense of their experience (cf. Boland and Weick)? How do they re-embed the system and the distant social ties it creates (cf. Giddens)? From our analysis of the interview data we will attempt to answer these questions by outlining three different subjective ways (amongst others) of 'living with the MAS' (as an imperfect but shared system of representations)—-the political, incarnate, and negotiation way. However, before we proceed with this analysis and discussion we will offer some comments on our research methodology and provide some background to our case study.

\section{Some comments on methodology}

Phenomenology is mostly perceived as a research method (Creswell, 1997) used by a growing number of authors in organization studies (e.g. Van Mannen, 2002) and IS (e.g. Zuboff, 1989, Brigham and Introna, 2006, Whitley and Myers, 2002). This paper uses phenomenology as a theoretical framework (the work of Husserl and Henry discussed above) but also as a methodology. Indeed, we would argue that theory and method are intimately connected and cannot be separated. In other words we would argue that it is not possible to take a phenomenological 
approach to research and then not giving a phenomenological account of it. As such it was important for us also to reflect Henry's phenomenology in our research methodology-by this we mean to acknowledge the singular nature of affective subjective experience. Accordingly we did not look at Henry's phenomenology (or phenomenology in general) to provide us with 'patterns' or coding schema that would function to systemise our data collection or analysis-unfortunately this is often done with so-called 'phenomenological' data (Thomson, et al., 1989, 1990)

\section{The interviews}

In the spring of 2004 one of the authors spent a two months period immersed at Omega's head office to conduct research on management accounting practices and governance. Omega executives welcomed this study on the ground that they had implemented new financial reporting tools some time ago and were of the view that they needed an analysis of the present situation prior to undertaking further developments. The researcher was completely at ease with management control vocabulary, practices, techniques and instruments since he could build on his own two year experience as a management controller in the headquarters of a large French multinational company. Most of his time at Omega's headquarters was spent immersed with the management accounting team and several trips to Paris and Lyon airports were organised to interview sales managers and visit subsidiaries' offices, local sales points, and warehouses. Thirty four people were interviewed (see list in Appendix). Interviews (all extensively transcribed) were semi-structured and would typically last between 1 and 2 hours. The interview typically started with questions on the interviewees' contribution to budgeting and forecasting exercises before taking a more informal turn. All questions were open- 
ended in order to develop a "sym-pathetic" presence. The respondents were not only given the opportunity to speak about their work with regard to the MAS they were also encouraged to express their affective experience (through questions such as "how did you feel when...." One might say that the interviews were openended dialogues rather than specific questions that expected specific responses. In these open-ended dialogues subjective affective responses were treated as equally legitimate to rational or cognitive responses-utmost care was taken not to privilege the one over the other, to allow the interviewee to move from the one to the other as they felt appropriate.

\section{Co-generative analysis of the interviews}

The approach to data collection was only one element of our phenomenological approach. The data analysis was also inspired by Henry's phenomenology. Over the course of several months two of the authors had a regular dialogue based on extracts from the interviews. We initially selected extracts from the interviews that seem to express the duplicity of abstraction and affectivity as described by the interviewees of their daily work with the MAS at Omega. During these first readings we were cautious not to simply impose Henry's 'phenomenological categories' onto the accounts. It was important for our phenomenological analysis not to reduce singular lived experiences to the ideal limit shapes of our intellectual categories. The multiple readings were guided by a principle of fidelity that allowed the text (interviewee) to retain its (their) singular voice.

Initially we expected to become aware of the negative impact of the abstract world of the MAS as it impinged on the lived experience of the participants. However, we 
soon realised that this was a much too simplistic view of the data. In subsequent readings we worked with the hypothesis (or rather intuition) that different livedexperiences may be related to different roles within the organisation. But we soon discovered that this was not the case. We did however notice that a certain coherence of experience seem to have emerged between different 'couples' of actors. It might have been possible to create a taxonomy of different 'types' but we resisted this and instead adopted the notion of different 'ways' (or modes of living). We deliberately focused on only a few such ways (many more were possible). Thus all extracts of interviews presented below come from the testimonies of nine (9) individuals with different, very singular, lived experiences. The selection of these individuals and 'ways of doing' makes no claim to any universal essence apart from the fact that all respondents were affected in different but also somewhat similar ways. Thus, the entire analysis phase was conducted in the form of a co-generative dialogue (Depraz, 2003) in which there was a co-generative interplay between the theoretical horizon (Henry's phenomenology) and the narratives of the interviewees (their singular lived experience). ${ }^{11}$ In this ongoing dialogue there was never a subordination of the one over the other. Rather they vitalised each other to bring about new understanding and insight as to the meaning of living with abstract numbers.

Clearly Henry's phenomenology is not the only theoretical horizon worthy of application to the case. We would argue, nonetheless, that is seems to provide us with original insights-on the intertwining of the absence and presence-without

\footnotetext{
${ }^{11}$ The two discourses with their own validity claim may develop in a 'co-generative' way if they are allowed to empower each other reciprocally. However, the horizon of such co-generative dialog is living praxis, which places a limit on any speculation.
} 
overloading us with analytical categories, as we hope will be apparent from our discussion below.

\section{Some background on Omega}

Omega is a subsidiary of a multinational company listed on the Paris Stock Exchange. It has specialized in travel retail, selling products such as perfume, cosmetics, spirits and tobacco in shops located in airport terminals. Omega runs over 100 sales points at French airports and employs about 1200 collaborators. For each airport terminal, Omega has appointed an operational manager who, as far as budgets and financial results are concerned, works with a management controller based at the headquarters. All airport terminals share a common MAS used to forecast future activities and report actual results to the headquarters. Forecasting is a particularly important budgeting exercise. Four times a year, all managers are asked to estimate their future sales over the coming 12 months. Simultaneously, management controllers work on expected costs. All the data is then collected and processed into the MAS to obtain an overall picture of expected profits.

\section{The importance of MAS in Omega}

As in most retail companies, every Omega employee is focused on the "Sales per Passenger" ratio (SPP). ${ }^{12}$ Operational managers tend to somehow 'translate' their intuitive knowledge of situations into SPP ratios that contribute to the mathematical representations of the future. At the time of the study, figures collected from operational managers were processed using the new MAS that had been in use

\footnotetext{
${ }^{12}$ The SPP ratio being the average amount spent in Omega shops or outlets per passenger.
} 
for approximately two years. The MAS proved to be very helpful to controllers from the headquarters who communicate actual results and estimates every trimester to investors and shareholders who are therefore provided with permanently updated projections against which to evaluate actual achievements. All "discrepancies" between forecasts and actual sales at a terminal are then likely to be precisely attributed either to changes in traffic - for which Omega is largely dependent on the airlines and the airport company - or to changes in the SPP - for which sales people and managers are held responsible. Thus, corporate managers find themselves in a position where they, through the MAS, have mediated access to local knowledge, i.e. to overcome their time-space distanciation by 'lifting out' the operational activities from their specific localized contexts. One of the consequences of this explicit and permanent comparison between actual results and expected ones is to turn the forecasts into the basis for wide-ranging incentive programmes central to most rewards and blame policies in the company.

What we find is that the 'forecast' is looked at very differently from the perspective of the different actors involved. Boardroom managers tend to share the practice and expectation of working on abstract representations of the firm's activities, rather than on the activities themselves-i.e. to govern at a distance. They do this in a context of a wide range of often conflicting priorities. They are struggling to cut down costs and inventories, increase profits, allocate resources in the best possible way, and to secure the shareholders' long-term commitment. As such forecasts need to reflect Omega's potential growth and to satisfy shareholders' expectations. Thus, the forecasts represent an amalgamation of possibilities and 
expectations in which each are shaped by the other. For example, some estimates proposed by controllers and operational managers might be considered either too optimistic or too conservative bearing in mind the expectations of the financial markets. In practice, as it is often the case, top managers change the figures in order to satisfy the shareholder's dominant view of what 'good management' is (Roberts and Scapens, 1985) i.e. to deliver, year after year, steadily increasing profits.

"To me, good forecasts are the ones that meet the shareholders' expectations and that are consistent with the company's strategy in terms of costs and profits perspectives".(Barry, CEO)

In contrast to this, operational managers are first and foremost faced with unexpected events such as changes in flight schedules, refurbishments of sales points, employee absences, and so on and so forth. To them, forecasts are only the best possible representations of future possible outcomes which are highly dependent on unforeseeable events. Yet, it is the MAS and its combination of actual figures and forecasts that will determine their contribution.

All information flowing from an operational level to boardroom management is 'translated' into memos and reporting charts on screens and on paper by controllers. Controllers are the only human interface between top managers and operational managers. Focusing on the controllers' work experience and on those of their counterparts (operational managers) in the terminal, we will now present the different "lived experiences" that are characteristic of the work relationships between controllers, operational managers and MAS. 


\section{Living with the teleology of abstraction and one's teleology of life}

\section{A political experience of working with MAS}

Muriel (Controller 1) has been in her present position for more than 3 years now. When describing her activities, she immediately stresses the differences in objectives among the different people involved in the forecast process. She sees herself as being involved in "a political game" between people with different, essentially utilitarian, behaviours. She explicitly mentions that both top managers and local managers have opposite interests: top management's intention is to show ambitious forecasts to shareholders, while local managers favour conservative forecasts to increase their chances of over-performing and getting bonuses. Muriel mentions that operational managers anticipate and make calculations that are likely to minimize their forecasts to make sure that, even if the Chief Financial Officer (CFO) increases it a little, they can still meet the target in the end.

“The operational staff's view isn't always the same as Finance's view because they don't have the same goals. We have to act as middle-men: we need to have a more objective view on the business because they get a bonus which is determined by the budget..." (Muriel, Controller 1)

On the other hand, she expects top management to be aware of this anticipatory behaviour of operational managers. Thus, she would tend not to change the operational forecast proposals as she anticipates the fact that the top managers will support their own agenda by proposing optimistic but uncertain expectations.

"To find the right balance we know that some operational managers are very pessimistic so we get them to go up. Optimists are a rare breed but CFOs are very 
optimistic. We virtually have to let the pessimists be pessimistic so that the CFO will bring them up.“ (Muriel, Controller 1)

Thus, according to her these anticipatory calculations make her controllers' job particularly difficult.

“The amendments are usually purely political: we can't whitewash the facts when results are bad. But we try to remain optimistic when times are hard (...) if we hope that, say, price changes will work in our favour, we increase the revenue a bit. It's not an operational modification but a strategic one. But in the end I'm the one who changes the sales figures and everything has to be changed at the last minute we're thrilled about that (sarcastic)" (Muriel, Controller 1)

Because top management interferes with the forecasts to limit differences between forecasts and the expectations of the financial market, she feels deprived of her role of interpreting and appreciating the proposals of the operational managers. She therefore complains about having to merely accept the amendments of top management without having a say in the matter.

"Sometimes I prepare something for the budget and they do things differently, and sometimes I don't agree and in that case I become very detached from what I've done." (Muriel, Controller 1)

She limits excessive movements, either way, as much as possible without any real cooperation from anyone. She further suggests that in this "game" the operational managers do not mobilize their knowledge of local contingencies to support their forecasts as they have no faith in their ability to affect the decisions of top managers. She feels therefore that she has no relevant information to report from the field to the higher levels of management. Operational managers tend to accept any changes imposed on them from above without defending their position: they adopt a loyal but fatalistic attitude. 
"Our role as an interface between the operational managers and Finance is to smooth things over. If the budget is too low and they (top management) mess up, they're (operational managers) happy, and if it's higher, well, they're used to it now and they just give up." (Muriel, Controller 1)

\section{An incarnated experience of working with MAS}

Mike (Controller 2) joined Omega some 18 months ago after a first few years' experience as a financial controller in the air travel business. He is now in charge of Omega's largest airport terminal where Mark (Ops. Manager 2) is in charge of all the Spirits and Tobacco shops. Mike bases his forecasting on strong and clear principles. He advocates the idea that the forecast must take into account local contingencies instead of blanket adjustments.

"Our aim is to use the data in a realistic way that is consistent with overall economic targets. The method is clear and open, with plenty of room for dialogue. But last time, after the operational manager's proposal, we had to make a few quick overall corrections which weren't realistic for the sales outlets. If we make too many corrections, we get lost." (Mike, Controller 2)

Having no previous experience in retail, he tends to have very direct relationships with the operational managers he works with, and he seizes every opportunity to spend time with them on site.

"I work directly with the (...) operational managers mainly. It's a team effort and we rely on one another a great deal (...) I try to go to the airport once a month to visit the shops, give them a hand setting up. Next Tuesday a remodelled shop is 
opening, so everyone's coming to lend a hand moving, which will be a good way of getting to know everyone as well as the sales outlet." (Mike, Controller 2)

Mike does not hesitate to challenge the accuracy and fairness of the SPP formula and to suggest modifications to it. It is a well-known fact among operational managers that not all the shops are located in the same part of the terminals and this has an impact on SPP levels. Some sales points are right in front of customs whilst others are tucked away in corners. Mike managed to learn from Mark and succeeded in showing top management the link between different SPP levels and the position of sales points. Although this effort did not change the SPP formula it did contribute to a better understanding of the figures by the top management. As a direct result they started to lobby airport management to get access to better locations instead of simply blaming poor results on operational management.

This way of knowing from experience and doing "face-work" with colleagues is totally shared by Mark (Ops. Manager 2), who claims to pay a lot of attention to face-to-face communication at work.

"We use e-mail a lot - at the expense of interpersonal skills, and that's an understatement (...) I'm one of those managers who believes that it's people who make up the system (...) Man is at the heart of the system: he's the one who optimises it - or not, as the case may be. The system should be adapted to suit the people who make it work. (...) E-mails can be handy but I prefer face-to-face communication by far. Via e-mail we communicate about anything and everything: it's dangerous. We delegate without control. I hate e-mail (...) I like to meet people, I see them, I visit the shop, we talk about this and that and that's how I build up my business. Management is all about people." (Mark, Ops. Manager 2) 
With this common way of living and working, Mike and Mark develop cooperation via regular informal contact and face-to-face meetings. Consequently when top management change the forecast without notification, he expresses how he is really affected.

"Naturally, when we spend time putting together a realistic budget we're not thrilled when it's all changed (irony). When people ask us to be more optimistic we have no choice, we just get on with it. We don't have any qualms about it, we say: "ooh dear, it's going to be tough" because we thought the first version was the right one but we do it. (...) We can change (forecasts) for reasons of strategy or future possibilities or God knows what - I don't even want to know ${ }^{13}$ but (...) we keep quiet and just take it because it's our job." (Mark, Ops. Manager 2)

In these situations Mark is forced to abandon his situated knowledge and stay loyal to his company even though he may suffer from goals set up from above, which are disconnected from his and his team lived reality.

\section{Negotiating reality through MAS}

It has also been three years since Janet (Controller 3) started her job at Omega. She says that she has developed quite close relationships with operational managers in that time. She is well aware of the problems related to the abstract dimension of her job and thus makes a point of having regular face-to-face contact with operational managers to keep herself abreast of their precise problems.

$13 \quad$ In French : « ou de je ne sais quoi et je ne veux pas le savoir » 
"There is an operational side to this job, because even though we do spend days on end poring over figures, we see the buyers and the operational managers and so are still involved at an operational level, which means we're not just dealing with abstract ideas all day. We're required to be very independent in our particular area and find out exactly why things aren't going well." (Janet, Controller 3)

During the forecast process, she is nonetheless well aware of the fact that she is under the authority of top managers who have their own constraints to be incorporated into the forecasts. She sets up the requirements from top management within which some sort of negotiation with operational managers can develop.

"In these negotiations we do have some influence because I tell the managers that it won't work because you need to be higher than the original forecast [...] It's easy to know what [top] management wants and so we lean towards their way of thinking and they [the operational managers] put a stop to that because things can get a little tough when we start off pretty high...." (Janet, Controller)

In this negotiation process she gives her operational managers the opportunity to justify their local decisions to top management from their real life context.

"To prepare my forecasts I mention that my terminal will be refurbished. I also mention that last year we had the war in Iraq and so on. I write a whole list on a sheet of paper with all the important elements such as the move of the Tel Aviv flight to another terminal explaining a loss of so many Euros with an impact on the SPP of so much. I also mention that the double labelling (duty free or not) will have such an impact on sales (...) I also mention that with less flights to care about, my team will 
have more time to take care of my clients who need information" (Judith, Ops. Manager 3)

Helping managers to elaborate the figures from their specific and situated context is also a way to help them to use the figures when they need to argue with their directors. In this way she is perceived as a partner by the operational managers she works with.

"If we go way over I call my director to explain that - let's say - that with the mobile perfume shop, I had to hire a few more temps and that's really exciting for the table - we didn't use to have that. It's interesting to see what room for manoeuvre he has. We look at all the costs." (Judith, Ops. Manager 3)

Another way she manages the negotiation process is to propose specific improvement projects which will make it possible for the unit to meet the forecasts.

"It's really interesting because we have an operation going with Financial Control and Purchasing to increase sales as quickly as possible and it has an immediate impact on the Profit and Loss account and the other tools. We set targets in the shops in order to budget in particular areas." (Judith, Ops. Manager 3)

In spite of all her efforts Janet is not always in a position to prevent last-minute changes. She suffers as much as the operational managers from these top-down decisions which often prevents her from doing meaningful follow up of actual results. Living praxis is then subordinated to what appears as abstract imperatives.

"There are so many people that can modify the figures without asking me. If only we would stick to the figures decided with the operational manager, we would really 
have a close look at the differences between actual figures and forecasts but now..." (Janet, Controller 3).

Now that we have looked at these three different responses to 'living with abstract numbers' (and there are many more) we would suggest that these experiences are not just minor idiosyncratic differences but rather singular significant differences as revealed by Michel Henry's phenomenology. Let us consider them in more detail.

\section{Discussion: Re-embedding MAS while being affected}

One might be tempted to say that senior managers live in the 'unreal' world of abstraction and operational managers live in the real world of everyday reality. One might also add that it is the complicated problem for the controllers to try and reconcile (or translate) between these two different worlds-i.e. the classical role of middle management. Such a more 'dualistic' account can and has been done before (Floyd \& Wooldridge, 1992; Mintzberg, 1994). However, it would be our argument that such an account, although not incorrect as such, would tend to miss uncovering the more subtle, but very significant, lived experiences that Henry's phenomenology will allow us to account for in the not unfamiliar organizational context of MAS in Omega.

From this phenomenological perspective we would claim that all the actors (at all levels) are deeply affected, in a very profound way, by the world they encounterin and through the abstractions of the MAS and by their embodied lived experience at the same time. They are all trying-to greater or lesser degree-to 
make the abstractions reflect (rather than deny) their own affective subjective reality-living at the same time with both the teleology of abstraction and the teleology of their life. If this was not the case then the MAS would not be the powerful social technology that it self-evidently is for the actors in the case, and has been argued by Miller (2001) and Miller and O'Leary (1993). For us it is important to reveal the variety of ways in which all the actors try to live this simultaneity. We will show how phenomenology will allow us to become aware of this simultaneity without simply turning such an account itself into another limitshape or abstraction. This is obviously an ever present danger for all accounts (indeed for all accounting more generally).

Thus, we start by acknowledging that all the actors are affected, even determined, by the MAS in very specific and singular ways. As Henry suggest: "it is therefore exact to ascertain that social determinations [such as the MAS] "determine" the individual to its innermost beings... and that determination consists in the fact that they are lived, felt, experienced (éprouvées in French) by every individual" (Henry, 1990: 104-105 our translation). Henry's phenomenology gives us good reason to acknowledge, and underline, the singularity of every respondent's affectedness. As proposed by Henry, "differences that arise from the irreducible individuality of a living subjectivity are entirely different from social differences" (Henry, 1990: 105, our own translation). If we take this seriously we can avoid simply reducing these individual differences to 'types'. Nevertheless, within the context of the irreducible nature of individual subjectivity we might still be able to discern or suggest, to some degree at least, some 'similarities' in these experiences—one might say different ways of dealing with this simultaneity. 
We would suggest that all the actors are acutely aware that the abstract numbers in the MAS will move across the boundaries of time and space-in other words we would say that actors in contemporary organisations have become reflexively aware of the ongoing working out of time-space distanciation (as suggested by Giddens). They anticipate that these numbers will become seen by others at a different time in a different place within a different praxis. They anticipate that these figures will affect these others, whom are already affected by their own subjective experience of their life as lived. For example the executives already anticipate how the shareholders and potential investors might be affected by the figures. This is their focus of concern, that which defines them as 'executives'. They want the figures to reflect (and not deny) this reality-although they also immediately know it cannot really do that. The operational managers also already anticipate that the controllers and executives will be affected by the figures in the MAS in accordance with their own praxis. Likewise they also want the figures to reflect (and not deny) this reality, even though they, like the executives, know it cannot.

Now, if the only relevant reality was the reality of abstract limit-shapes then they could simply 'fiddle the figures' in line with these anticipated expectations. This is however never the case with abstractions that function, and have its being, in the living praxis of organizational actors. Managers also know that what makes those figures matter to them (why they concern themselves with them) and to others in the first instance is that they all believe and already anticipate that these figures do in some way reflect lived praxis itself-these figures are entangled with the 
everyday praxis of being a manager and its various related affects. Indeed, they all already realise, and anticipate, that their working lives are intertwined with these figures in some way or another. Nevertheless, they also feel simultaneously that these figures do not, and cannot, reflect the singularity of the life they are living when they do what they do when they are 'working with forecasts at Omega.' It is this simultaneity that is at the heart of our phenomenological analysis. Let us now consider in more detail these three different ways of being affected-of working out this simultaneity —within the context of working with the MAS outlined above. Let us then consider how these ways of being affected frame the way the system is re-embedded, or not, within trustful relations.

Muriel (controller): As was argued above, acting in large increasingly globalised organizations, in organizations shaped by modern management techniques, we tend more often than not to rely on abstract representations to govern across time and space. Furthermore, these abstractions are always - by their very nature-a reduction of our and others' living praxis. As Boland (1993b) did, we observe that actors need to re-embed these representations into their ongoing living praxis as an active and ongoing act of interpretation. Muriel, at first glance, seems to interpret figures with the unaffected subject-object distance (the phenomenality of vision one might say) which is characterized by a certain rational objectivity: "operational staff view... finance view... them...objective view". With Henry's phenomenology it is possible to render intelligible, and accounts for, this specific effort of interpretation. From the perspective of affectedness we can say that these representations-even though she seems to treat them as 'objective'-do affect Muriel's life and affects her living praxis. The evidence for this claim can be seen 
in her own words when she talks about "bad results", "hard times", "happy operational managers", "hope", "remain optimistic", and so forth. In other words, Muriel, in living the life she lives as a controller, is bound to be affected by the MAS's representations and figures. Nonetheless, her affectedness (as opposed to her seeming objectivity and distance) only becomes visible once we take note of what the phenomenology of Henry reveals to us. The numbers in MAS are not only for coordinating representations, objectives and bonuses. It is also a way of intertwining her living praxis within the web of the living praxis of all relevant others. She explicitly refers to her position as being a 'middleman', with all the tensions such a position normally includes. She lives her praxis as the inter-'face.' As an inter-'face' she sees herself as the one who re-embeds the MAS and its numbers within the web of optimistic and pessimistic bonus driven managers and profit driven top executives. As a living being, affected by these representations, she is likely to find the force for taking action (to engage with these representations) in her affective subjectivity. Her way to try and live with the affecting tension (the simultaneity) inherent to her inter-'face' position is to focus on the 'quality' of the representations. She tries to get "an objective view on the business", and tries to "find the right balance" between operational managers and top managers through the numbers in the MAS. In her affected subjectivity she reinterprets the process of elaborating the figures as a way "to smooth things over" by finding some sort of an equilibrium. Using numbers as a mechanism to resolve conflict appears then as an affective choice to smooth over the differences. Indeed we would suggest that, in more general terms, abstract representations such as the mathematical Walrassian market and Tayloristic time and motion studies should be seen as affective choices-i.e. not a necessary choice for 
efficiency as such-but rather as mechanisms for smoothing over tensions in the organization or society more generally (Shenhav, 1999).

When top managers modify the representations, Muriel experiences a malaise from the growing discrepancy between those representations and her anticipated perception of the situation. This instrumental use of the figures, to impose difficult objectives, may ruin her relation and trust with the operational managers. When she feels that she has no means to reduce the gap between the 'difficult' figures and her affective perception of the situation she modifies her interpretation of the situation by using commonly understood and 'ready-made' theories. She, for example talks about it as a "political game". She also becomes sarcastic: "we're thrilled about that". Also, to protect herself she attempts to "become very detached from what I have done" which leads her to inaction. Changing her interpretation of the situation alters her range of possible actions. It allows her to keep herself away from exchanges-as a "political game" she feels it does not implicate her. However, as Henry suggests, we cannot detach ourselves from our affectedness. Simply changing our interpretation of the situation may be an unreal (life-less) way to deal with the situation. Mark and Mike, to whom we now turn, suggest some other possibilities.

Mike (controller) and Mark (manager): Where Muriel tries to balance the lived tension and pain by dealing with the numbers in the MAS as the "objective view on business", the explicit focus of Mike is "to use the data in a realistic way". What is the meaning of this 'realism' one might ask? Mike reports that he acts with the sales teams in key moments. For example, he "gives them a hand setting up" and 
"lend a hand moving" in order to prepare a remodelled shop for opening. This is his preferred way to make sense of the numbers. For him it is: "a good way of getting to know everyone as well as the sales outlet"-phenomena appear to him through the sharing of incarnated praxis. We can therefore suggest that this realism for him means to locate the real at the level of praxis and co-praxis. To locate it in the shared difficulty of action and efforts as lived by affected persons in their specific work context (i.e. phenomenality of affectedness or the teleology of life).

Nonetheless, we should be careful not to simply reduce this phenomenality of affectedness - the sharing of incarnated praxis-to notions such as 'tacit' or 'implicit' knowledge (as is often done). Rather, the location of the real in the phenomenality of affectedness allows for an altogether different way of reembedding the representations of the MAS in the real. As Adler, reviewing Henry, suggests: "representation renders present again what praxis immediately presents" (Adler, 1985: 156). Sharing - even partly - the lived action enables them to establish the abstract budget as "a team effort" where operational managers and him "rely on one another a great deal", this is a "method... clear and open, with plenty of room for dialogue". Where Muriel experiences herself as a middleman that can achieve safety from the inherent tensions by attempting to produce-through her expertise and judgement-exact representations, Mike derives his confidence from sharing with the teams their lived incarnate reality.

When the figures are altered by top management it is not his inner confidence that is in question. He does not need to look for a 'ready-made' interpretation of the 
situation, as Muriel does. He only observes that the corrections "weren't realistic for the sales outlet", accepting the risk that the figures may lose their meaning. Indeed, he suggests that if these changes or corrections, which occur as shift/changes in the abstract world, do not find their translation in the real lifeworld then they "get lost". This is also a question of affective life energy. Indeed, abstract representations do not generate, per se, the strength to tackle challenging objectives. Rather, this comes from living praxis itself. For example, Mike found the energy to challenge the unrealness of the SPP formula-by showing that it created an unfair assessment of the different shops-because he was already affected by a shared lived experience of these differences in living praxis. This example illustrates how controllers, who in some way share lived praxis, could act in a domain beyond merely being middlemen (as Muriel seems to believe).

Mark is also affected by the governmental control of abstract system such as MAS. In dealing with these abstractions he suggests that "its people who make up the system", that "Man is at the heart of the system: he's the one who optimize it or not, as the case may be". In these remarks he seems to recall what Henry would consider the site of value creation-human living praxis. This has specific consequences for the way he works. He rejects abstract and anonymous information which is transferred by e-mail "I hate e-mail" and focuses on "interpersonal skills", face-to-face encounters, meetings, visits, talks, and so forth. This is his preferred way to share real life experiences, to find solutions, to achieve cooperation and so forth. In contrast to his approach he claims that "the system should be adapted to suit the people who make it work". As such he dedicates significant time to get a budget which will reflect and help living praxis "we spend 
time putting together a realistic budget". For him the figures are a path not an end destination in itself. It seems clear that both Mark and Mike express undoubtedly their view that abstractions must find their vital meaning in living praxis (i.e. they see the importance of 'face-work' as suggested by Giddens (1990).

It is certainly worth noting the frequent use of the pronoun "we" in Mikes sentences. In contrast Muriel tends to mostly use the pronoun "they". We would suggest that the sharing of living praxis enables the achievement of a certain unity of differences (manager and controller) which is not the case with the approach of Muriel, which is rather to achieve "objective" figures. We might describe the way of Mike and Mark relates to figures as a 'realistic' approach. By this we mean that they tend to take for granted the already ongoing living praxis as the basis for interpreting, evaluating and responding. They also tend to place their emphasis on making the figures reflect, rather than deny, at least in some way, their shared living praxis. In this way, both the figures in the MAS and the controller's comments provide a clear sense of the level of performance they are confident they can deliver. However, they still need to deal with the fact that the figures can, and will almost inevitably, become unrealistic.

Mark's way to react to such changes in the figures is first and foremost affective and rooted in living praxis: "we're not thrilled when it's all changed", we say "ooh dear, it's going to be tough". Because the previous forecasts were built on a realistic basis changes to these are immediately perceived by Mark-at the affectedness level-as requiring intense effort. Given the way Mark relates to the world, the representations (figures and targets coming through the MAS) are 
always already interpreted and valued by him as they appear in the light of his life. One might say that his consciousness is always informed (i.e. judgement and interpretation) via the affectedness of his living praxis. Thus, we would suggest that-although differently for Muriel, Mike and Mark-the interpretation of the figures always assumes affectedness (the teleology of life) as its original source of meaning-i.e. it is not interpretation (or the interpretive process) as such that creates meaning, as is so often argued by authors in the information systems and information science disciplines. These operations of consciousness have as their necessary condition, and their teleology, the subjective and affective life of the lifeworld (as argued by Husserl and Henry). Of course distant senior management must be careful not to impose abstractions on the living praxis of employees so that those objectives that are valued as "tough" do not become valued as "impossible". This might lead to a situation where the figures are simply dismissed as 'abstract numbers' that mean 'very little if at all' and as such become ignored.

Janet (controller) and Judith (manager): Janet makes a clear distinction between abstract representations (phenomenality of representation) and shop floor events: "even though we do spend days on end poring over figures, we see the buyers and the operational managers... which means we're not just dealing with abstract ideas all day". She expresses clearly her need to re-embed the figures through face-work with managers. Nevertheless she also seems to understand top management's expectations as expressed in the figures: "It's easy to know what Management wants and so we lean towards their way of thinking". She sees her role as trying to 'find out exactly why things aren't going well' (according to figures). Thus, taking into consideration "abstract ideas" and the 
'operational managers' lived experience she lives her organisational life as a negotiator who "feels" the limits of the abstract numbers by listening to the living praxis of operational managers: "they (the operational managers) put a stop to that [changing of figures] because things can get a little tough when we start off pretty high...."

Janet takes time to listen, she helps managers to represent their particular circumstances in the forecast figures in order to make them realistic with respect to their living praxis, as Judith (operational manager) explains: "To prepare my forecasts ... I also mention that last year we had the war in Iraq and so on. I write a whole list on a sheet of paper with all the important elements ... I also mention that with fewer flights to care about, my team will have more time to take care of my clients who need information." Judith finds the input from Janet very satisfying because it allows her to demonstrate, through the figures, her intimate knowledge of business life as well as allowing her to establish forecasts (representations) coherent with her lived experience ("reality" in her words): "The whole point (of the forecasts) is to stick to reality: it's very gratifying to show that I know my business." The knowledge she gains through elaborating the abstract representations also helps her to justify, through the figures, her local decisions to her director: "If we go way over I call my director to explain... that's really exciting for the table - we didn't use to have that". Judith lives an affective experience, a kind of excitement at being able to argue through these abstractions. Janet also brings external solutions to 'improve the figures' in order to avoid the situation where managers would find it 'too tough': "we have an operation going with Financial Control and 
Purchasing to increase sales [figures] as quickly as possible and it has an immediate impact on the Profit and Loss account".

Although the main level of discussion that Janet and Judith draw upon when discussing the MAS seems to be 'the figures' it also seems clear that the underlying basis for making sense of these 'figures' is the living praxis of the managers. It seems that the goal of a 'good negotiation' is to reach a sort of equilibrium between the abstract figures required and liveable practices-the teleology of abstraction and the teleology of people life as Henry would say. Such a process of reaching an agreement creates a sense of mutual responsibility "We usually call each other before we change anything"(Judith). In such a context decisions taken by top management, without prior communication, leads to a lot of dissatisfaction: "Then we hear on the grapevine that the budget has been changed. It's a pity we weren't told over the phone first". In such cases life experience becomes subordinated to what appears as abstract imperatives and Janet suffers because of a lack of consideration for her work being altered by "so many people... without asking me". As a consequence she is not motivated to account for the discrepancies between actual figures and forecasts: "we would [normally] really have a close look at the differences between actual figures and forecasts but now...." (Janet).

To sum up: in the three different (but somehow similar) experiences presented above we see managers dealing with the abstract numbers of the forecasts in different ways. They are all aware (as most managers are) that these numbers do not necessary reflect their and their team's living praxis. Indeed a lot of the 
interpretation, negotiation, discussion, etc. that surround these figures is informed by this deviation or tension between the duplicity of abstract numbers and living praxis. The outcome in these cases are however very different. At one level of analysis these differences might be dismissed as different emotional responses, which have little to do with the problem of "getting the job done". Such a response, not uncommon, misses the very important insights that Henry's phenomenology of life provides. What these cases show us is that the suffering, joy, pain and malaise that emerge from this intertwinement of abstract reality and living praxis is the real stuff of organisational behaviour. It is the very ground that grounds all interpretation, discussion, negotiation and agreement (or disagreement). If we deny, or dismiss it, we will miss what is most essential. Affectedness is the source rather than the outcome of dealing with disembedding organising practices-or time-space distanciation-in increasingly abstract organisational landscape (for example the emergence of evidence based management (Pfeffer \& Sutton, 2006) and audit cultures (Strathern, 2000)). Subjective affective life thus appears as the ontological ground that renders possible the re-embedding (and re-embodying) of abstract systems in time-space distanciation-the intertwining of the abstract and the lifeworld.

\section{Some conclusions and implications}

If one accepts Henry's phenomenology as a legitimate account of the experience of life in organisations then one might ask what the implications would be if one would take such an approach seriously? There are many but we will only highlight a few here. In terms of information systems we would suggest that accepting this approach might call for a shift from the hegemony of rationality (based on abstract 
numbers) to a situation in which reasonableness based on teleology of people life is given equal legitimacy-to acknowledge that the real value of knowledge derives from living praxis rather than from abstract codifications. This is not to say that abstract knowledge and rationality is wrong or illegitimate. It is rather to suggest that it is its hegemonic status that needs to be questioned. This is, however, not necessarily a humanistic call or endeavour, although it might be construed this way. It is rather a suggestion that the denial of the power of living praxis will in the long run undermine the vital energy of life itself and lead to a systematic condition of malaise—which might manifest itself as stress or anxiety or even in the nihilistic excesses of hyper capitalism. One might suggest that evidence of this is already appearing, for example, in the rapidly increasing levels of absenteeism in many contemporary organisations and in the nihilistic excess of the recent credit crunch. More specifically, if we accept Henry's account then we ought to design organising processes in such a way as to create opportunities for living praxis to be legitimately shared. One would certainly advocate for more regular face-to-face meetings, or "facework rituals" as Giddens refers to it. However with Henry we suggest that it is not just more meetings which are needed, but meetings where the legitimacy of reasonableness is acknowledged, and where forms of dialogue that allows for the sharing of feelings and concerns are respected and encouraged. Having said this we must emphasise again that we are not calling for sentimentalism-which is associated with superficiality and instrumentalism in equal measure-but for the possibility of discernment in the light of one's affective life and its teleology. This call is grounded in Henry's phenomenology and its decisive reversal of traditional western thought: "It is not consciousness (derived from objective knowledge) which determines life, it is life 
which determines consciousness" (1976: 401). This is, we would suggest, the only way to relate to the reality of everyday organisational life, i.e. to be realistic. Indeed we would claim that when knowledge is not merely derived from general frameworks but from lived, incarnated experience, unexpected innovation may indeed occur. As Henry asserts: "one should not start from what people say, imagine, ... one should start from really active people and from their real vital process" (1976: 403). Thus, we would suggest, with Henry, that realism is not first and foremostly about or in the 'facts' but in the dynamism of life itself. If we really take this seriously then the design of 'information systems' that indeed 'inform' would be very different. The current emphasis on analysis and method might be replaced by an emphasis on practices as practiced. Even when information or knowledge by necessity needs to be abstract (through ERP or MAS systems for example) and our interactions meditated through abstractions (through e-mail for example), information, to be powerful, needs not only to be reembedded but also, in a radical way, re-embodied (in the affective flesh as it were).

For us as researchers Henry's phenomenology also has many implications. First we might say that we need not be caught in the debate between the positivistic approach (based on lifeless abstract representations) and a relativistic interpretative approach which is often critiqued for providing "just another interpretation". As researchers we can ground our (participant) observations in the teleology of our life, in subjectivity and not subjectivism. This offers us a critical standpoint, which is different from the Habermassian logic of argument. We can do research, in an axiologic starting point, from the real of life (which manifests itself through people suffering, caring, being excited, elated, bored, and so forth). This is 
the ongoing challenge for us as researchers-i.e. to make our research real, or at least speak of the real.

With this work we are able to legitimise what has become illegitimate through the massive expansion of scientific management and governmental practices. For us it is a radical transformation from the pervasive abstraction and distanciation of work (brought about by information and communication technology) to the meaninggiving source of work, which is affective life itself. We would suggest that organisation studies (and managers) would make a fatal mistake to ignore the work of Henry.

\section{References:}

Adler, P. (1985). Neither Consciousness, Nor Matter, but Living Bodily Activity, (review of Michel Henry, Marx: A Philosophy of Human Reality), Graduate Faculty Philosophy Journal, 10(2),147-161.

Boland, R.J. (1983b). "The in-formation of information systems", in Boland, R.J. and Hirschheim, R.A., Eds. Critical Issues in Information Systems Research, John Wiley \& Sons, New York.

Boland, R.J. (1984). Sense-making of accounting data as a technique of organizational diagnosis, Management Science, 30(7), 868-882.

Boland, R.J. (1987). "The in-formation of information systems," In Critical Issues in Information Systems Research, R.J. Boland and R. Hirschheim (Eds.) John Wiley \& Sons, New York, pp. 363-379.

Boland, R.J. (1991). "Information System Use as a Hermeneutic Process," In Information Systems Research: Contemporary Approaches and Emergent 
Traditions, H-E. Nissen, H.K. Klein, R.A. Hirschheim (eds.), North Holland, Amsterdam, pp. 439-464..

Boland, R.J. (1993b). Accounting and the interpretative act, Accounting

Organization and Society, 18( 2/3), 125-146.

Boland, R.J. and Pondy, L.R. (1983a). "Accounting in Organizations: A Union of Natural and Rational Perspectives", Accounting Organizations and Society, 8(2/3), 223-34.

Brigham, M. and Introna, L. (2006). "Hospitality, improvisation and Gestell: a phenomenology of mobile information" Journal of Information Technology, $21(3), 140-153$.

Brunsson, N., (2006). Mechanisms of Hope. Maintaining the Dream of the Rational Organization, Copenhagen Business School Press, Liber, Stockholm.

Ciborra, C.U. (1998). 'Crisis and foundations: An inquiry into the nature and limits of models and methods in the information systems discipline', Journal of Strategic Information Systems, 7(1), 5-16.

Ciborra, C.U. (1999). 'Notes on improvisation and time in organizations', Accounting, Management and Technologies, 9(2), 77-94.

Ciborra, C.U. (2004). The Labyrinths of Information: Challenging the wisdom of systems, Oxford, Oxford University Press.

Ciborra, C.U. (2000). From Control to Drift, Oxford: Oxford University Press.

Cooper, R. (1992). Formal Organization as Representation: Remote Control, Displacement and Abbreviation. In M. Reed and M. Hughes (Eds.) Rethinking Organization. London, Sage: 254-272.

Creswell, J. (1997). Qualitative inquiry and research design: Choosing among five traditions. Thousand Oaks, CA: Sage Publications. 
Damasio, A. (1994). Descartes' Error. New York, New York: Grosset/Putnam.

Depraz, N., Varela, F., Vermersch, P. (2003) On becoming aware. A pragmatics of Experiencing, Amsterdam: Benjamin Press.

Dreyfus, H. (1991). Being-in-the-World: A Commentary on Division I of Heidegger's Being and Time. Cambridge, MA, MIT Press

Feldman, M. S., \& Pentland, B. T. (2003). Reconceptualizing Organizational Routines as a Source of Flexibility and Change. Administrative Science Quarterly, 48(1), 94-118.

Fleischman, R.K, Tyson, T.N (1993). "Cost accounting during the industrial revolution: the present state of historical knowledge", Economic History Review, 46(3), 503-17.

Floyd, S. W., \& Wooldridge, B., (1992). 'Middle Management Involvement in Strategy and its Association with Strategic Type: A Research Note', Strategic Management Journal, 13 (special issue), 153-167.

Foucault, M. (1997). Security, territory, and population. In M. Foucault, Ethics:

Subjectivity and Truth, trans. R. Hurley and others., ed. P. Rabinow, 67-71. New York: The New Press.

Frandsen, A-C. (2009). 'From psoriasis to a number and back', Information and Organization, Vol. 19(2), 103-128.

Gabriel, Y. (2002). "Essai: On paragrammatic uses of organizational theory: A provocation". Organization Studies, 23(1), 133-151.

Giddens, A. (1984). The Constitution of Society. Berkeley, University of California Press.

Giddens, A. (1990). The Consequences of Modernity. Stanford, CA: Stanford University Press 
Henry, M. $(1963,1973)$. L'Essence de la manifestation, PUF, Paris ; The Essence of Manifestation, Transl. Girard Etzkorn, The Hague, Nijhoff., Henry, M. (1976, 1983). Marx, Une philosophie de la réalité, Vol. I. Paris: Gallimard; Marx, A Philosophy of Human Reality, trans K. McLaughlin. Bloomington: Indiana University Press.

Henry, M. (1985, 1998). Généalogie de la psychanalyse, PUF, Paris ; The Genealogy of Psychoanalysis, trans. D. Brick. Stanford, CA, Stanford University Press.

Henry, M. (1987). La Barbarie, Grasset, Paris.

Henry, M. (1990). Du communisme au capitalisme. Théorie d'une catastrophe. Odile Jacob, Paris.

Henry, M. (1999). « Material Phenomenology and Language (or pathos and language) », Continental Philosophy Review, 32(3), 343-365.

Henry, M. (2003) Phénoménologie de la vie, Tome I : De la phénoménologie, PUF, Paris.

Henry, M. (2004). Phénoménologie de la vie. Tome III: De l'art et du politique, PUF, Paris.

Hopwood, A.G. (1987). "The Archeology of Accounting systems", Accounting Organization and Society, 2 (3), 207-234.

Hummel, R. P. (2006). The triumph of numbers. Knowledges and the mismeasure of management. Administration and Society, 38(1), 58-78

Husserl, E. (1936, 1970). The Crisis of European Sciences and Transcendental Phenomenology. Northwestern University Press, Evanston, Illinois.

Ilharco, F. (2003). “The world through managers' goals: a phenomenological account of Data and Information", WM 2003, $2^{\text {nd }}$ Conference 'Professional 
Knowledge Management: Experience and Visions, April 2 - 4, 2003, Luzern, Switzerland.

Introna, L.D. (1997). Management Information and Power. London, Macmillan. Introna, L.D. (2001). Recognising the Limits of Virtual Organizations. In Hunt \& Barnes (eds) E-Commerce and V-business, Butterworth-Heinemann, pp. 268-278.

Jin, L., and Robey, D. (2008). "Bridging Social and Technical Interfaces in Organizations: An Interpretive Analysis of Time-Space Distanciation," Information and Organization, 18 (3), 177-204.

Jones, T.C., Dugdale, D. (2001). "The concept of an accounting regime", Critical Perspectives on Accounting, 12(1), 35-63.

Kallinikos (2006). The Consequences of Information: Institutional Implications of Technological Change. Cheltenham: Edward Elgar

Kallinikos, J. (1995). "The architecture of the invisible: technology is representation", Organization, 2(1), 117-40.

Latour, B. (1992). "Where are the Missing Masses? The Sociology of a Few Mundane Artifacts", pp. 225-258 in: Shaping Technology/Building Society: Studies in Sociotechnical Change, edited by W.E. Bijker \& J. Law, MIT Press, USA.

Lilley,S., Lightfoot, G. and Amaral, P. (2004). Representing Organization: Knowledge, Management, and the Information Age, Oxford University Press.

Linstead S., Westwood R. (2001). 'Meaning Beyond Language: Monstruous Openings', in R. Weswood and S. Linstead (eds) The Language of Organization. London: Sage. 
Miller, P. (2001). "Governing by Numbers: Why Calculative Practices Matter", Social Research, 68 (2), 379-396.

Miller, P. and O'Leary, T. (1987). "Accounting and the construction of the governable person" Accounting Organization and Society, 12 (3), 235-265.

Miller, P. and O'Leary, T. (1993). "Accounting expertise and the politics of the product: economic citizenship and modes of corporate governance" Accounting Organization and Society, 18 (2/3), 187-206.

Mingers, J. (2001). "Embodying information systems. The contribution of phenomenology", Information and Organization, 11(2), 103- 128.

Mintzberg, H., (1994). The Rise and Fall of Strategic Planning: Reconceiving Roles for Planning, Plans, Planners, New York.

Palmer, R. (1969). Hermeneutics: Interpretation Theory in Schleiermacher, Dilthey, Heidegger, and Gadamer. Evanston: Northwestern University Press.

Panteli, N. (2004). Discursive articulation of presence in virtual organizing, Information and Organization. 14(1), 59-81.

Pentland, B. T., \& Feldman, M. S. (2008). Designing routines: On the folly of designing artifacts, while hoping for patterns of action. Information and Organization, 18(4), 235-250.

Pfeffer, J. and Sutton, R.I. (2006). "Evidence-based management”, Harvard Business Review, 84(1), 63-74.

Roberts, J. and Scapens, R. (1985). "Accounting systems and systems of accountability - understanding accounting practices in their organizational contexts" Accounting, Organization and Society, Vol. 10, no. 4, pp.443-456.

Robey, D., Schwaig, K.S., and Jin, L. (2003). "Intertwining Material and Virtual Work," Information and Organization, 13 (2), 111-129. 
Schultze, U. and Orlikowski, WJ (2001). Metaphors of virtually: shaping an emergent reality. Information and Organization. 11 (1). 45-77.

Scott, SV and Wagner EL, (2003). "Networks, negotiations and new times: The implementation of enterprise resource planning into an academic administration," Information and Organization, 13 (4), 285-313.

Shenhav Y. (1999). Manufacturing Rationality: The Engineering Foundations of the Managerial Revolution, Oxford University Press, Oxford.

Sotto, Richard (1997). "The virtual organization." Accounting, Management and Information Technologies 7(1), 37-51

Strathern, M. (2000). Audit Cultures: Anthropological Studies in Accountability, Ethics and the Academy. London Routledge.

Taylor, F. W. (1911). The Principles of Scientific Management, New York: Harper \& Brothers.

Thomson, C., Locander, W.B., Pollio, H.R (1989). "Putting Consumer Experience Back Into Consumer Research" The Journal of Consumer Research, 16 (2), 133-147.

Thomson, C., Locander, W.B., Pollio, H.R. (1990). "The Lived Meaning of Free Choice" The Journal of Consumer Research, 17(3), 346-361.

Tomlinson, J. (1999) Globalization and Culture. Chicago, IL: University of Chicago Press.

Van Manen, M., (2002). Writing in the Dark: Phenomenological Studies in Interpretive Inquiry. The Althouse Press, London (Ontario, Canada).

Walsham, G. and Sahay, S. (1999). "GIS for district-level administration in India: problems and opportunities." MIS Quarterly. 23(1), 39-65.

Weick, K (1995). Sensemaking in Organizations. Thousand Oaks, CA:Sage. 
Weick, K. (1988). Enacted sensemaking in crisis situations. Journal of Management Studies, 25(4), 305-317.

Weick, K. (1993). The collapse of sensemaking in organizations: The Mann Gulch disaster. Administrative Sciences Quarterly, 38(4), 628-652.

Whitley, E. A. and Myers, M. D., (2002). Global and organizational discourse about information technology: Working Conference on Global and Organizational Discourse about Information Technology, December 12-14, 2002, Barcelona, Spain. Springer.

Zuboff S., (1989). In the Age of The Smart Machine, The Future of Work and Power, Heinemann, London. 


\section{Appendix: Schedule of formal interviews}

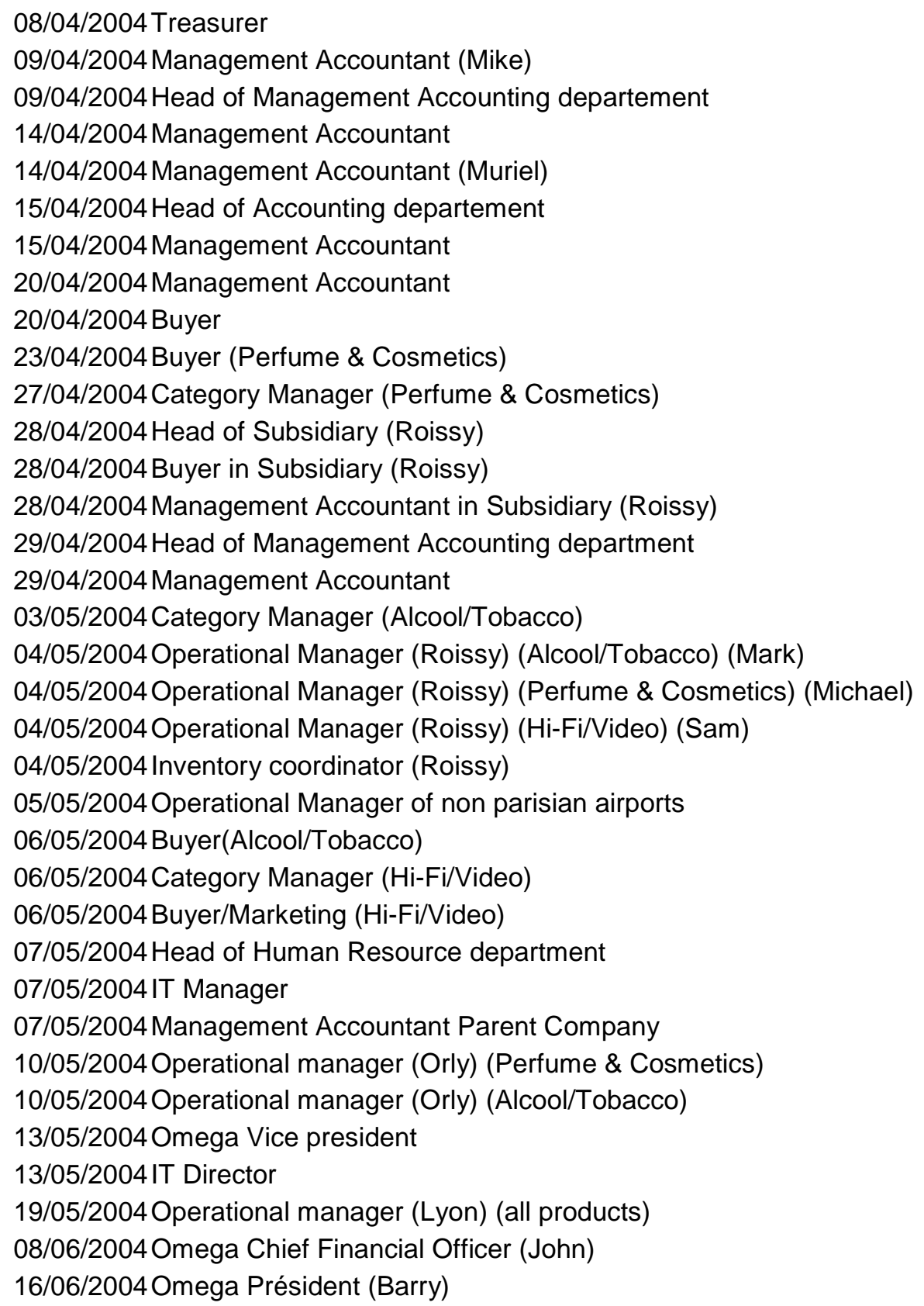

Only formal interviews are noted here. 